\title{
Ultrafast hydrogen migration in photoionized glycine
}

M.C. Castrovilli ${ }^{* 1,2}$, A. Trabattoni ${ }^{3,4}$, P. Bolognesi ${ }^{1}$, P. O'Keeffe ${ }^{1}$, L. Avaldi ${ }^{1}$, M. Nisoli ${ }^{3,2}$, F. Calegari $^{4,5,2}$ and R. Cireasa ${ }^{6}$

${ }^{1}$ Istituto Struttura della Materia, ISM-CNR, 00016 Monterotondo Scalo, Roma, Italy

${ }^{2}$ Institute for Photonics and Nanotechnologies, IFN-CNR, 20133 Milano, Italy

${ }^{3}$ Department of Physics, Politecnico di Milano, 20133 Milano, Italy

${ }^{4}$ CFEL-DESY, Notkerstrasse 85, 22607,Hamburg, Germany

${ }^{5}$ Department of Physics, University of Hamburg, 20355 Hamburg, Germany

${ }^{6}$ Institut des Sciences Moleculaires d'Orsay, CNRS, Universitè Paris Sud, Orsay France

email: matteacarmen.castrovilli@ism.cnr.it; francesca.calegari@desy.de; raluca.cireasa@u-psud.fr

\begin{abstract}
Hydrogen migration in the glycine cation has been investigated using a combination of a short train of attosecond extreme ultraviolet pulses with few-optical-cycle near-infrared pulses. The yield of the photofragments produced has been measured as a function of pump-probe delay. These time-dependent measurements reveal the presence of a hydrogen migration process occurring in $48 \mathrm{fs}$. Previous mass spectrometric experiments and theoretical calculations have allowed us to identify the conformations and cation states involved in the process induced by the broad band extreme ultraviolet radiation.
\end{abstract}

\section{TOC:}

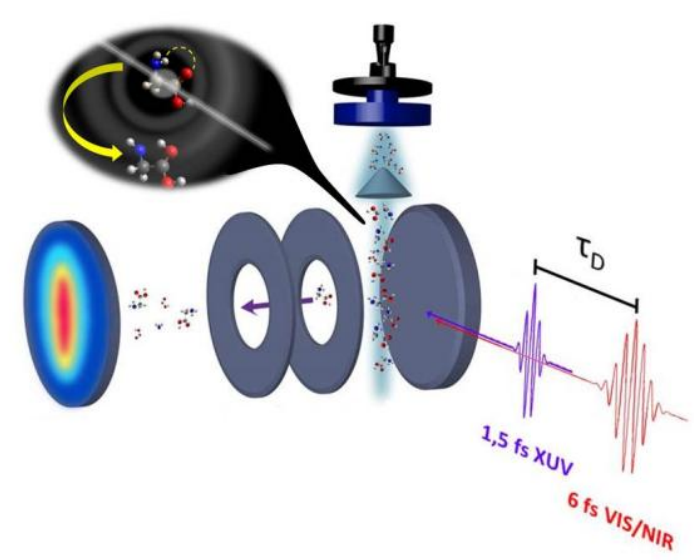

The study of isolated amino-acids in the gas phase allows for complex processes to be probed down to their fundamental molecular properties. Most amino acids present a high degree of conformational flexibility associated with their backbone and side chains, with many local minima in the torsional potential-energy surface. The resulting conformational variety determines the three-dimensional structure of a protein and thus its functionalities. ${ }^{1}$ 
The $\alpha$-amino acids contains two functional groups, a carboxyl $(\mathrm{COOH})$ and an amino $\left(\mathrm{NH}_{2}\right)$ group bonded to a central carbon atom, the so-called $\alpha$ carbon $\left(\mathrm{C}_{\alpha}\right)$. As structural units that make up proteins, they play an important role in an enormous variety of life processes and metabolic reactions. Among the amino acids, glycine $\left(\mathrm{NH}_{2} \mathrm{CH}_{2} \mathrm{COOH}\right)$ is the simplest one ${ }^{2}$ with a single hydrogen atom as a side chain of the $\mathrm{C}_{\alpha}$, and it is often used as a prototype to disentangle physical processes occurring in more complex amino acids. In particular, the knowledge of its structure and reactivity is crucial to understand the role of transient species involved in protein radical catalysis as well as the effects of oxidative damage in proteins ${ }^{3}$ initiated by ionizing radiation. ${ }^{4,5}$

In this context, the investigation of the very first instants following the interaction of glycine with extreme ultraviolet (XUV) radiation can provide a direct insight into processes, such as intramolecular hydrogen transfer, that in a peptide may lead to oxidative damage. Previous studies have shown that removing an electron from the neutral system modifies both the acidity and the basicity of the groups involved in the hydrogen bridge bond, in such a way that it is difficult to establish how this hydrogen bond would be affected by oxidation. ${ }^{6-10}$

The effects of the ionizing radiation on the relative stability of the glycine conformers, of $\mathrm{C}_{\mathrm{s}}$ and $\mathrm{C}_{1}$ symmetries, and on the intramolecular hydrogen transfer process have been theoretically investigated using several different approaches. ${ }^{11-16}$

The photoionization induced dynamics of two conformers has been analysed on the picosecond time scale by a classical trajectory simulation ${ }^{17}$ and recently Ayuso et al. ${ }^{18}$ theoretically studied the ultrafast electron dynamics induced by attosecond pulses. Several papers have been devoted to the study of the ionization and fragmentation of glycine by synchrotron and VUV He(I) radiation ${ }^{19,20}$, electron ${ }^{12,21}$, multiply charged ions s2,14 $^{22}$ and $\mathrm{fs}_{1} \mathrm{aser}^{23}$, as well as to the competition between ultrafast $\mathrm{H}$ migration and Coulomb explosion in glycine dications by collisions with multiply charged ions ${ }^{14}$. No direct investigations of the processes occurring at the early times of glycine photoionization have been reported in the ultrafast time domain so far.

Attosecond technology now enables the investigation of the primary relaxation processes involving electronic and nuclear degrees of freedom and their coupling ${ }^{24}$, with unprecedentedly high temporal resolution. This has been recently demonstrated in the case of the phenylalanine amino acid where isolated attosecond pulses of XUV radiation were used to trigger prompt ionization. The observed periodic variation of the charge density around the amine group was attributed to the coherent excitation of a few 1-hole cationic states by the broadband XUV pulse and the electronic wave packet created was probed by femtosecond pulses. ${ }^{25}$ With the same experimental approach the non-adiabatic relaxation as well as the nuclear rearrangement following the ionization by an XUV attosecond pulse train have been demonstrated for 5-Fluoro- and 5-Bromo-Uracil radiosensitizers ${ }^{26,27}$ and DNA building blocks such as thymine and thymidine $^{28}$, and it could be used in the future to investigate the ultrafast dynamics in model systems for the DNA-protein interaction such as 5-Benzil-Uracil. ${ }^{29,30,31}$

Here we present a time-resolved study of intramolecular hydrogen migration in glycine triggered by the sudden ionization induced by an XUV attosecond pulse train and probed by few-femtosecond near-infrared (NIR) pulses.

The photofragmentation mass spectra obtained using either NIR or XUV pulses are shown in Figure 1 (top and bottom panels, respectively). In the multiphoton NIR mass spectrum the most intense peaks correspond to the parent ion and the aminomethyl cation $\left[\mathrm{NH}_{2} \mathrm{CH}_{2}\right]^{+}$at the mass-to-charge ratios $(\mathrm{m} / \mathrm{z}) 75$ and 30 , respectively. The NIR pulse allows the ionization and the breaking of the $\mathrm{C}_{-} \mathrm{C}_{\alpha}$ bond with release of the $\left[\mathrm{NH}_{2} \mathrm{CH}_{2}\right]^{+}$cation and the $[\mathrm{COOH}]^{\circ}$ radical. ${ }^{16}$ The XUV mass spectrum is significantly richer than that generated by the NIR pulses due to the pulse bandwidth $(16-50 \mathrm{eV})$ which enables the access to higher excited states of the cation leading to different and more extensive dissociation pathways. In both mass spectra, the peak of the $\left[\mathrm{NH}_{2} \mathrm{CH}_{2}\right]^{+}$fragment is the most intense one. Its appearance energy has been measured to be $350 \mathrm{meV}$ above the vertical ionization energy ${ }^{19}$, while theory predicts that it can be directly accessed after molecular ionization via a barrierless pathway. ${ }^{22}$ 
The breaking of the C-C $\alpha$ bond can also lead to another dissociative channel where the charge is on the $\mathrm{m} / \mathrm{z}$ 45 fragment assigned to $[\mathrm{COOH}]^{+\bullet}$. In the inset of Figure 1 the $\mathrm{m} / \mathrm{z} 45$ fragment is accompanied by the $\mathrm{m} / \mathrm{z}$ 46 fragment assigned to $\left[\mathrm{C}(\mathrm{OH})_{2}\right]^{+\bullet 19,20}$. The relative intensity of the $\left[\mathrm{C}(\mathrm{OH})_{2}\right]^{+\bullet}$ with respect to the $[\mathrm{COOH}]^{+\bullet}$ fragment in Figure 1 is about $9.4 \%$. This is consistent with previous mass spectrometry measurements ${ }^{19}$ and more recent photoelectron-photoion coincidence (PEPICO) experiments ${ }^{32}$, where the $\mathrm{m} / \mathrm{z} 46$ ion represents a minor fragmentation channel in the XUV energy region. In addition, the state-selected PEPICO spectra $^{32}$ showed that the formation of this fragment occurs in a narrow region of binding energy between 12.2 and $15.7 \mathrm{eV}$, where the ionization of the $4 \mathrm{a}^{\prime \prime}, 3 \mathrm{a}^{\prime \prime}, 14 \mathrm{a}^{\prime}$ and $13 \mathrm{a}^{\prime}$ orbitals occurs. Recent calculations ${ }^{18}$ of the state selected photoionization cross section showed that the largest contribution to the cross section in the energy range of the XUV pulse is given by the 14a' orbital. Moreover the calculations in ref. [33] showed that this orbital is delocalized along the $\mathrm{H}-\mathrm{O}-\mathrm{C}-\mathrm{C}-\mathrm{N}$ backbone and is affected by conformational process independently of the rotated bond. Thus a rotation around the $\mathrm{C} \alpha-\mathrm{N}$ bond can result in a conformation favourable for the $\mathrm{H} / \mathrm{H}^{+}$transfer from the $\mathrm{NH}_{2}$ moiety to the $\mathrm{COOH}$ one, as shown in the inset of Figure 1 .

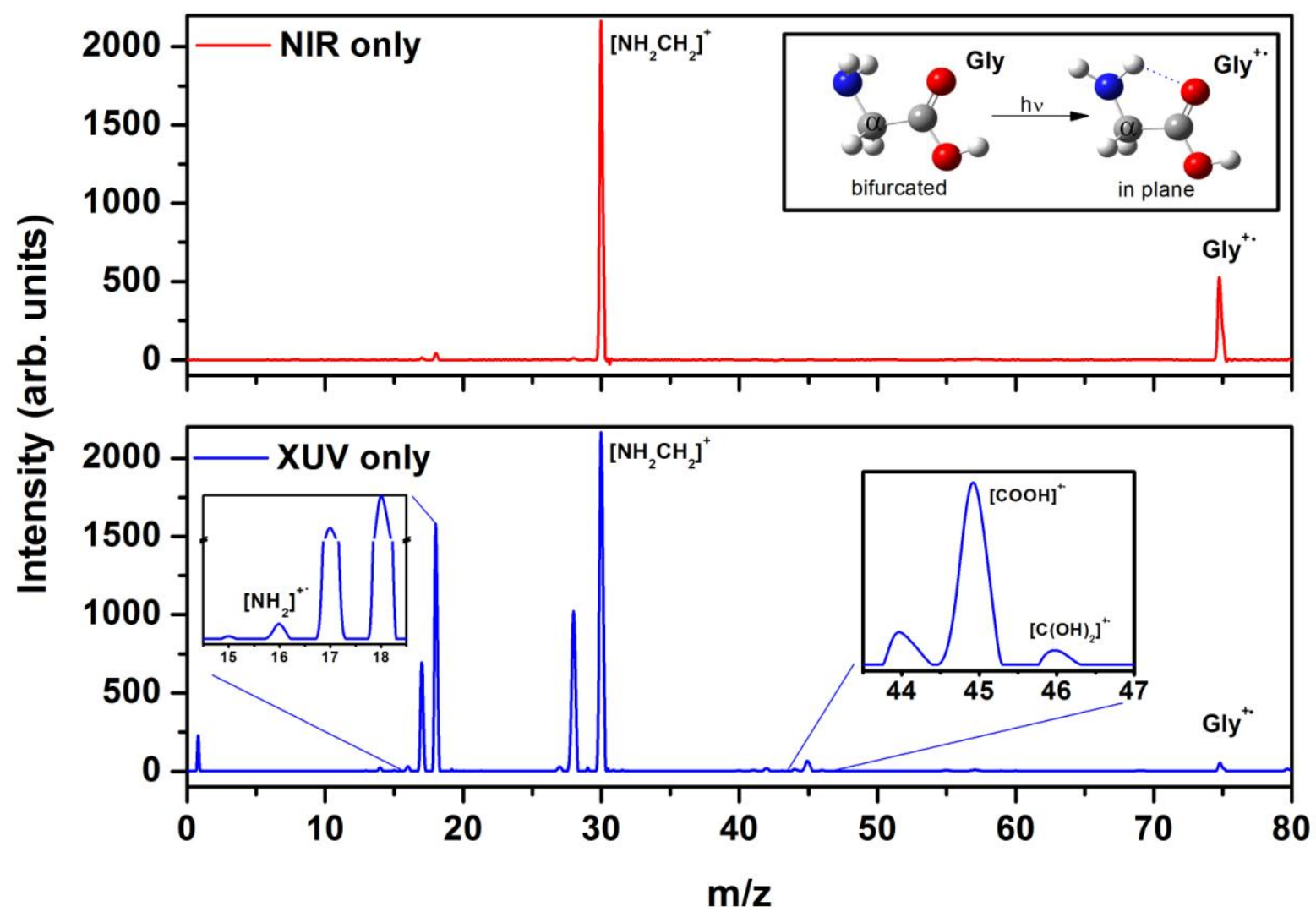

Figure 1. Mass spectra of glycine induced by NIR (top panel) and XUV (bottom panel) photoionization. The mass spectra have been normalized to the peak at $\mathrm{m} / \mathrm{z} \mathrm{30}$. The two insets in the bottom panel show the peaks at $\mathrm{m} / \mathrm{z} 16$ corresponding to $\left[\mathrm{NH}_{2}\right]^{+\bullet}$ and at $\mathrm{m} / \mathrm{z} 44,45,46$ corresponding to $\left[\mathrm{CO}_{2}\right]^{+},[\mathrm{COOH}]^{+\bullet}$ and $\left[\mathrm{C}(\mathrm{OH})_{2}\right]^{+\bullet}$, respectively. The inset in the top panel, shows the different conformations of glycine with the $\mathrm{NH}_{2}$ moiety which passes from bifurcated to in plane configuration after the ionization. The dotted line depicts the hydrogen bridge bond.

To investigate the dynamics of the $\mathrm{H} / \mathrm{H}^{+}$migration we have measured the time dependent yield of $\mathrm{m} / \mathrm{z} 45$ and 46 fragments as a function of the delay between the XUV pump and NIR probe pulses. To emphasise the temporal dynamics of the process the ion yields in Figure 2a have been presented on a [0,1] scale, by subtracting a flat background from the raw data and normalizing the resulting maximum value to one. In order to be formed, the $\mathrm{m} / \mathrm{z} 46$ fragment requires an $\mathrm{H} / \mathrm{H}^{+}$transfer reaction leading to an isomer of the glycine cation. The calculated interconversion barriers ${ }^{22}(1.56 \mathrm{eV})$ between the canonical and the isomeric forms of the cation in the ground state are significantly lower than the energy of the XUV pulse. 
The XUV ionisation of glycine can trigger the isomerisation, with a hydrogen migrating to the carboxyl oxygen and the creation of the fragment at m/z 46, as confirmed by the XUV mass spectrum in Figure 1. These complementary dynamics have been fitted using the convolution of an exponential decay function, $P(t)$, with a Gaussian function, $G(t)$, representing the cross correlation signal between XUV and NIR pulses:

$$
S(t)=B+A \cdot P(t) \otimes G(t)
$$

where $B$ is the background, $A$ is the amplitude of the signal and $P(t)$ is given by the following expression:

$$
P(t)=\left(e^{-\frac{t-T}{\tau_{\text {decay }}}}\right) \text { or }\left(1-e^{-\frac{t-T}{\tau_{\text {rise }}}}\right)
$$

where the time constant $\tau_{\text {decay/rise }}$ represents the decay or rise time of the dynamics and $\mathrm{T}$ corresponds to the shift with respect to the zero time delay. By fitting the dynamics of fragments $\mathrm{m} / \mathrm{z} 45$ and 46 we retrieved a decay time $\tau_{\text {decay }}=49.5 \pm 2.7 \mathrm{fs}$ and a rise time $\tau_{\text {rise }}=47.9 \pm 1.7 \mathrm{fs}$, respectively, which indicates that the time required for the hydrogen to be transferred is approximately $48 \mathrm{fs}$.

In order to investigate if it is a proton or a neutral $\mathrm{H}$ which is involved in the isomerization, the temporal dynamics of the $\mathrm{H}^{+}$has been investigated. Within the statistical uncertainty of the data no temporal dynamics is observed for the $\mathrm{m} / \mathrm{z} 1$ fragment. This however does not exclude the $\mathrm{H}^{+}$transfer because the proton may never become so loosely bound to dissociate.
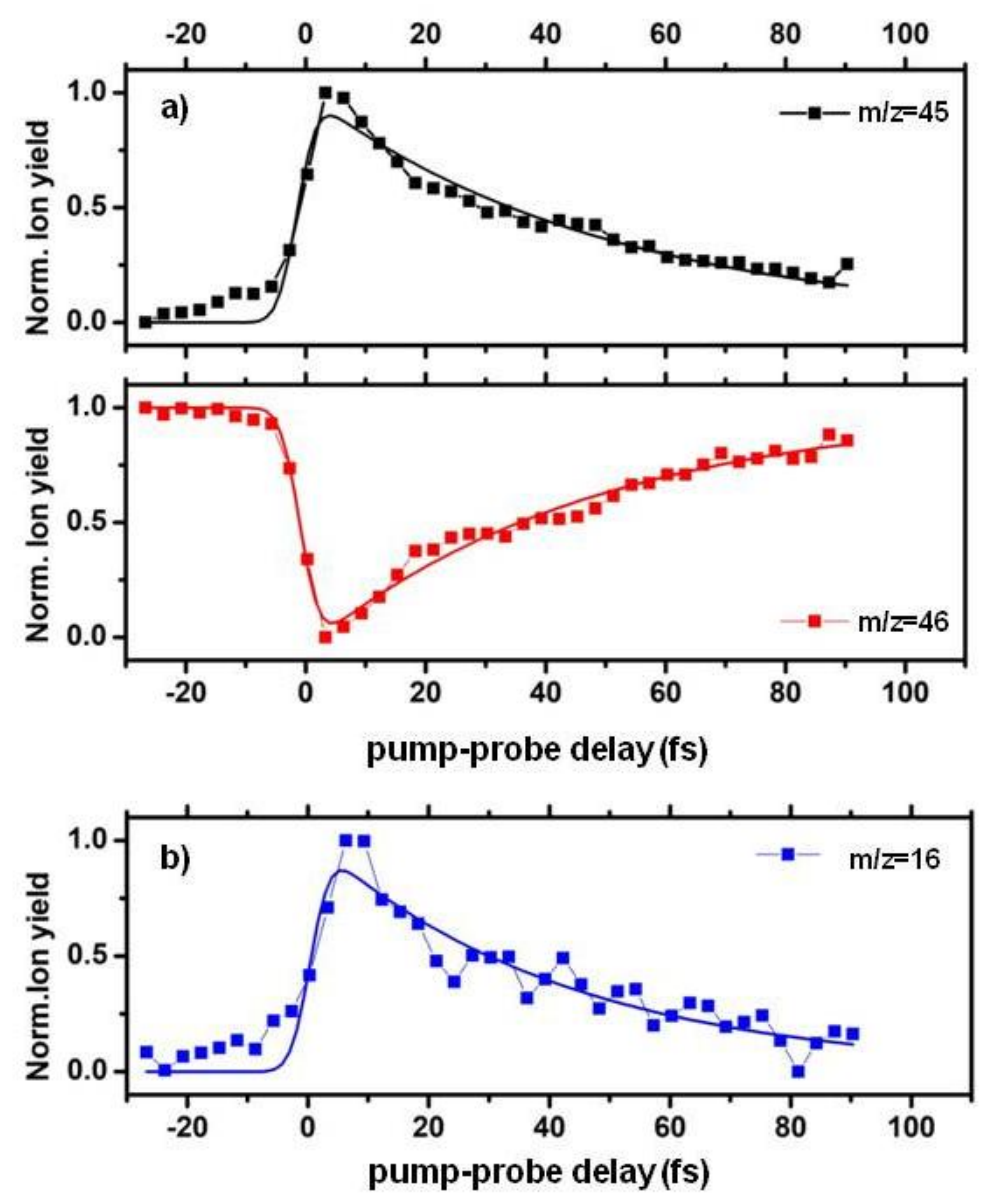

Figure 2. Integrated ion yield as a function of the pump-probe delay for fragments at $\mathrm{m} / \mathrm{z} 45$ (a, black dotted line), 46 (a, red dotted line) and 16 (b, blue dotted line). Positive time delay values correspond to interaction with the XUV pulse first followed by the NIR pulse. The solid lines represent the fitting curves. The variation in the yields of the $\mathrm{m} / \mathrm{z} 45,46$ and 16 are $54.4 \pm 1.8,41.4 \pm 1.1$ and $36.8 \pm 1.6 \%$, respectively. 
The isomerization in glycine has been commonly described in the literature as originating from the $\mathrm{C}_{\alpha}$ site to produce either the enol form $\left[\mathrm{NH}_{2}=\mathrm{CH}-\mathrm{C}(\mathrm{OH})_{2}\right]$ (Figure 3a) or the $\left[\mathrm{NH}_{3}-\mathrm{CH}-\mathrm{COOH}\right]$ isomer (Figure 3b) ${ }^{14}$. We propose the alternative pathway involving $\mathrm{H} / \mathrm{H}+$ transfer from the amino group directly to the carboxyl oxygen atom as also suggested by ref. [17] (Figure 3c).

a)

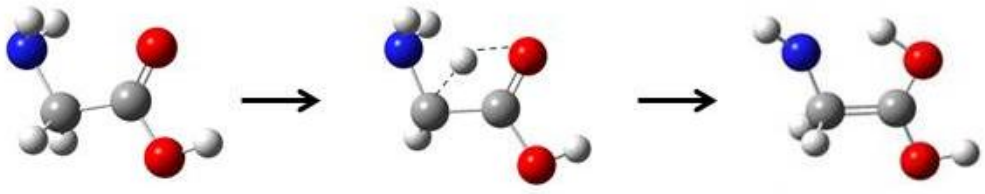

b)
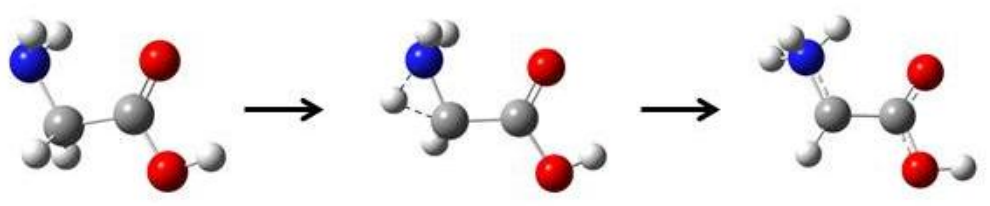

c)
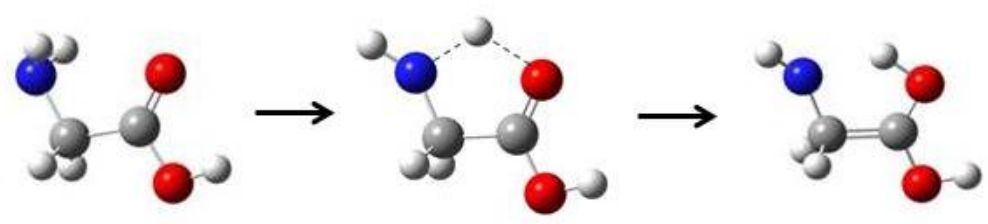

Figure 3. Schematic of the isomerization mechanisms described in ref. [14] involving the migration from the Ca to the carboxylic group (a) or to the amino group (b). The alternative pathway described in ref [17] involving the transfer from the amino group directly to the carboxyl oxygen atom (c).

In order to shed light on this point we analysed the dynamics of fragment at m/z 16 shown in Figure $2 \mathrm{~b}$. Both $\left[\mathrm{NH}_{2}\right]^{+\bullet}$ and $\mathrm{O}^{+}$ions can contribute to the $\mathrm{m} / \mathrm{z} 16$ peak. Fitting the signal with the functional used for the $\mathrm{m} / \mathrm{z}$ 45 fragment, we infer a time constant of $\tau_{\text {decay }}=41.9 \pm 7.6 \mathrm{fs}$, very similar to that of the $\mathrm{m} / \mathrm{z} 45$ fragment. We attribute the variation in the yield of the peak at $\mathrm{m} / \mathrm{z} 16$ to the contribution of the $\left[\mathrm{NH}_{2}\right]^{+\bullet}$ ion. This suggests that fragments at m/z 16 and 45 are involved in the same process, where the former acts as hydrogen "donor" and the latter as hydrogen "acceptor".

This picture might be supported by the results of Kuleff et $\mathrm{al}^{34}$ who predict that the charge migration in glycine occurs through a pure hole-mixing mechanism involving the orbitals $13 \mathrm{a}^{\prime}$ and $14 \mathrm{a}^{\prime}$. Initially the hole is created in orbital $14 \mathrm{a}^{\prime}$, which is spread over the entire molecule, but has its highest density located on the $\mathrm{N}$-terminal moiety. After a few femtoseconds more than $90 \%$ of the hole is transferred to the orbital $13 \mathrm{a}^{\prime}$, which is localized mainly on the carboxyl $(\mathrm{COOH})$ group. Then the process continues in reverse order until the charge has returned back to its initial position in $t \approx 7 \mathrm{fs}$. Despite the fact that the charge oscillations are faster than nuclear rearrangement, they nonetheless determine the effective potential seen by the nuclei and therefore may drive the $\mathrm{H}$ transfer between the $\mathrm{NH}_{2}$ and $\mathrm{COOH}$ moieties leading to the formation of the $\mathrm{m} / \mathrm{z}$ 46 fragment.

The present experimental observation can be interpreted considering all the possible calculated conformers of the neutral and ionized glycine. ${ }^{11,10}$ Among them, the structure in which the $\mathrm{O}-\mathrm{H}, \mathrm{NH}_{2}$, and $\mathrm{CH}_{2}$, groups are in their normal orientations, with a bifurcated hydrogen-bonding arrangement, has been identified as the lowest in energy and the most stable in the neutral molecule..$^{10,13}$

In the ionization process, a rotation around the $\mathrm{C}_{\alpha}-\mathrm{N}$ bond changes the orientation of the $\mathrm{NH}_{2}$ group from the bifurcated configuration to an in-plane arrangement (see inset in Figure 1) in order to form one of the most stable radical cation structures ${ }^{10}$. It has been calculated that the ionization of the bifurcated structure leads to a first-order saddle point that evolves to the structure in which the $\mathrm{NH}_{2}$ and $\mathrm{C}=\mathrm{O}$ groups lie on the same 
plane $^{10}$. This rearrangement influences the hydrogen bonds involving the amine group, with an increase of the $\mathrm{NH}_{2}$ acidity as the intramolecular hydrogen bonds in which $-\mathrm{NH}_{2}$ acts as proton donor is strengthened. Therefore the hydrogen bond between the $\mathrm{NH}_{2}$ and the carboxyl oxygen atom $(\mathrm{N}-\mathrm{H} \cdots . . \mathrm{O}=\mathrm{C}$, Figure 1) can be considered to be strongly stabilized in the glycine radical cation and responsible for the complementary dynamics on fragments 45,46 and 16 .

It is interesting to note that the time constants determined here are similar to the 30 fs estimated for the $\mathrm{H}$ migration by Maclot et al. ${ }^{22}$ in the Coulomb explosion of glycine dications in fragments $\mathrm{H}_{2} \mathrm{NCHCO}^{+}(\mathrm{m} / \mathrm{z}$ 57) and $\mathrm{H}_{2} \mathrm{O}^{+}(\mathrm{m} / \mathrm{z}$ 18) as well as with the isomerization time of about $50 \mathrm{fs}$ measured in the acetylene cation by the absorption of extreme ultraviolet pulse with the duration of about $30 \mathrm{fs}$ at the Free Electron Laser in Hamburg. ${ }^{35}$

In conclusion, the sudden ionization of a molecule by broadband XUV pulses, inevitably leads to the coherent superposition of a large number of electronic states ${ }^{18,24,25}$ with the direct result that many dissociative channels become active. However, the selectivity conferred by the photoionization crosssection ${ }^{18}$ and the possible conformation of the cation limit the number of significant channels contributing to the measured dynamics.

We showed that a typical ultrafast pump-probe measurement can be exploited to tackle the hydrogen migration process occurring in ionized glycine. The analysis of the complementary dynamics of the fragments with $\mathrm{m} / \mathrm{z} 45$ and 46 enabled us to determine the time scale of $\mathrm{H}$ migration to be about $48 \mathrm{fs}$. On the grounds that the dynamics of $\mathrm{m} / \mathrm{z} 16$ fragment, $\left[\mathrm{NH}_{2}\right]^{+\bullet}$, occurs on a similar timescale, we suggest that a $\mathrm{H} / \mathrm{H}^{+}$ of the amine group is involved in the process. This conclusion is further supported by the large cross section of the $14 \mathrm{a}^{\prime}$ orbital, its charge distribution and a conformation in which the $\mathrm{NH}_{2}$ and $\mathrm{C}=\mathrm{O}$ groups lie on the same plane.

The results of this work proved that a technology based on trains of attosecond pulses is suitable to investigate nuclear rearrangement in addition to electron dynamics. This represents a step forward in the real-time observation of the chemical rearrangements and transition states in systems of biological interest.

\section{EXPERIMENTAL METHODS}

Near-infrared (NIR), 5 -fs pulses centered at $750 \mathrm{~nm}$ with $2.5 \mathrm{~mJ}$ energy, $1 \mathrm{kHz}$ repetition rate and a residual single-shot CEP fluctuation of $\pm 200 \mathrm{mrad}$ (rms) were obtained by hollow-core fiber compression of $25 \mathrm{fs}, 6$ $\mathrm{mJ}, 800 \mathrm{~nm}$ pulses $^{36}$. A portion of the NIR beam (70\%) was focused into a static gas cell filled with krypton to produce a short train of XUV attosecond pulses (estimated overall duration of $1.5 \mathrm{fs})^{37}$ by high-order harmonic generation. A $100 \mathrm{~nm}$ thick aluminium filter was used to filter out the fundamental radiation and the energy region of the spectrum below $16 \mathrm{eV}$. The remaining portion of the NIR beam (30\%) was time delayed by using a piezo-stage and then collinearly recombined with the XUV beam by using an interferometric approach ${ }^{25}$.

The molecular beam of isolated and neutral glycine molecules was generated by evaporation from a cylindrical oven interfaced with a pulsed Parker valve operating at $100 \mathrm{~Hz}$ and equipped with an adjustment mechanism in order to optimize the vapor densities directly on the signal. The oven and the valve are assembled in a set-up described in ref.[27]. The sample was sublimated at $170^{\circ} \mathrm{C}$ in the oven and the vapors produced were entrained out by a $\mathrm{Kr}$ pulsed beam provided by the Parker valve with a nozzle diameter of $500 \mu \mathrm{m}$. A 1-mm hole skimmer was used to select the central part of the molecular beam providing isolated and neutral molecules into the interaction region between the repeller and the extractor of a Velocity Map Imaging (VMI) spectrometer. The ions were extracted perpendicularly to the plane defined by the molecular and laser beam directions and detected by a pair of MCPs and a phosphor screen. The ion signal was 
collected from the phosphor screen, amplified and then sent to the acquisition system. The time of flight (TOF) spectra were recorded as a function of pump-probe delay with temporal steps of $3 \mathrm{fs}$.

\section{ACKNOWLEDGEMENTS}

The authors acknowledge support by the ERC Starting Research Grant STARLIGHT No. 637756, ERC Research Grant ELYCHE No. 227355, the "Laserlab-Europe" Integrated Infrastructure Initiative and the XLIC COST Action CM1204 through a Short Term Scientific Mission. We appreciate Dr. P. Çarçabal's contribution to the preparation stage of the experimental campaign.

\footnotetext{
${ }^{1}$ Berg, J.M.; Tymockzo, J.L.; Stryer,L., Biochemistry, Ed.5 ${ }^{\text {th }} .2002$

${ }^{2}$ Eulenburg, V.; Armsen, W.; Betz, H.; Gomeza, J. Glycine transporters: essential regulators of neurotransmission. Trends in Biochemical Science, 2005, 30, 325-333.

${ }^{3}$ Berlett, B. S.; Stadtman, E. R. Protein oxidation in aging, disease, and oxidative stress. J. Biol. Chem., 1997, 272, 20313-20316.

${ }^{4}$ Von Sonntag, C. The Chemical Basis of Radiation Biology; Taylor and Francis: London, 1987.

${ }^{5}$ Stadman, E. R. Oxidation of free amino acids and amino acid residues in proteins by radiolysis and by metal-catalyzed reaction. Annu. ReV. Biochem., 1993, 62, 797-821

${ }^{6}$ Sodupe, M.; Oliva, A.; Bertran, J. Theoretical Study of the Ionization of the $\mathrm{H}_{2} \mathrm{O}-\mathrm{H}_{2} \mathrm{O}, \mathrm{NH}_{3}-\mathrm{H}_{2} \mathrm{O}$, and FH$\mathrm{H}_{2} \mathrm{O}$ Hydrogen-Bonded Molecules. J. Am. Chem. Soc., 1994, 116, 8249-8258

${ }^{7}$ Sodupe, M.; Oliva, A.; Bertran, J. Theoretical Study of the Ionization of Phenol-Water and

Phenol-Ammonia Hydrogen-Bonded Complexes. J. Phys. Chem. A, 1997, 101, 9142-9151.

${ }^{8}$ Sodupe, M.; Oliva, A.; Bertran, J. Theoretical Study of the Ionization of the $\mathrm{H}_{2} \mathrm{~S}-\mathrm{H}_{2} \mathrm{~S}, \mathrm{PH}_{3}-\mathrm{H}_{2} \mathrm{~S}$, and ClH$\mathrm{H}_{2} \mathrm{~S}$ Hydrogen Bonded Molecules. J. Am. Chem. Soc., 1995, 117, 8416-8421.

${ }^{9}$ Rodrìguez-Santiago, L.; Sodupe M.; Oliva A.; Bertran J. Hydrogen Atom or Proton Transfer in Neutral and Single Positive Ions of Salicylic Acid and Related Compounds. J. Am. Chem. Soc., 1999, 121, 8882-8890.

${ }^{10}$ Rodrìguez-Santiago, L.; Sodupe M.; Oliva A.; Bertran J. Intramolecular Proton Transfer in Glycine Radical Cation. J. Phys. Chem. A, 2000, 104, 1256-1261.

${ }^{11}$ Csàszàr, A. G., Conformers of gaseous glycine. J. Am. Chem. Soc. 1992, 114, 9568-9575.

${ }^{12}$ Depke, G.; Heinrich, N.; Schwarz, H. On the gas phase chemistry of ionized glycine and its enol. A combined experimental and ab initio molecular orbital study. Int. J. Mass Spectrom. Ion Process., 1984, 62, 99-117.

${ }^{13}$ Yu, D.; Armstrong, D.A.; Rauk, A. Hydrogen bonding and internal rotation barriers of glycine and its zwitterion (hypothetical) in the gas phase. Can. J. Chem. 1992, 70, 1762-1772.

${ }^{14}$ Maclot, S.; Piekarski, D.G.; Domaracka, A.; Méry, A.; Vizcaino, V.; Adoui, L.; Martín, F.; Alcamí, M.; Huber, B. A.; Rousseau, P. et al. Dynamics of Glycine Dications in the Gas Phase: Ultrafast Intramolecular Hydrogen Migration versus Coulomb Repulsion. J. Phys. Chem. Lett., 2013, 4, 3903-3909.

${ }^{15}$ Gil, A.; Simon, S.; Rodrìguez-Santiago, L.; Bertràn, J; Sodupe, M.; Influence of the Side Chain in the Structure and Fragmentation of Amino Acids Radical Cations. J. Chem. Theory Comput., 2007, 3, 22102220.

${ }^{16}$ Simon, S.; Sodupe, M.; Bertran, J. Isomerization versus Fragmentation of Glycine Radical Cation in Gas Phase. J. Phys. Chem. A, 2002, 106, 5697-5702.

${ }^{17}$ Shemesh, D.; Gerber, R.B. Different chemical dynamics for different conformers of biological molecules: photoionization of glycine. J. Chem Phys. 2005, 100, 241104

${ }^{18}$ Ayuso, D.; Palacios, A.; Decleva, P.; Martin, F. Ultrafast charge dynamics in glycine induced by attosecond pulses. Phys. Chem. Chem. Phys., 2017, 19, 19767-19776.

${ }^{19}$ Jochims, H.W.; Schwell, M.; Chotin, J.L.; Clemino, M; Dulieu, F.; Baumgartel, H.; Leach, S. Photoion mass spectrometry of five amino acids in the 6-22 eV photon energy range. Chem. Phys. 2004, 298, 279297.

${ }^{20}$ Lago, A.F.; Coutinho, L.H.; Marinho, R.R.T.; Naves de Brito, A.; de Souza, G.G.B.; Ionic dissociation of glycine,valine and proline as induced by VUV (21.21) photons, Chem. Phys. $2004,307,9-14$.

${ }^{21}$ Junk, G.; Svec, H.; The mass spectra of the $\alpha$-amino acids. J. Am. Chem. Soc. 1963, 85, 839-845.
} 
${ }^{22}$ Maclot, S.; Piekarski, D.G.; Delaunay, R.; Domaracka, A.; Méry, A.; Vizcaino, V.; Chesnel, J.Y.; Martìn, F.; Alcamì, M.; Huber, B. A. et al. Stability of the glycine cation in the gas phase after interaction with multiply charged ions. Eur. Phys. J. D, 2014, 68, 149.

${ }^{23}$ Vorsa,V.; Kono, T.; Willey, K. F.; Winograd, N.; Femtosecond photoionization of ion beam desorbed aliphatic and aromatic acids:fragmentation via $\alpha$-cleavge reactions. J. Phys. Chem. B. 1999, 103, 7889-7895.

${ }^{24}$ Nisoli, M. ; Decleva, P.; Calegari, F.; Palacios, A; Martín, F. Attosecond Electron Dynamics in Molecules. Chem. Rev., 2017, 117, 10760-10825.

${ }^{25}$ Calegari, F.; Ayuso, D.; Trabattoni, A.; Belshaw, L.; De Camillis, S.; Anumula, S.; Frassetto, F.; Poletto, L.; Palacios, A.; Decleva, P.; et al. Ultrafast electron dynamics in phenylalanine initiated by attosecond pulses. Science, 2014, 346, 336-339.

${ }^{26}$ Castrovilli, M. C.; Trabattoni, A.; Bolognesi, P.; O’Keeffe, P.; Avaldi, L.; Nisoli, M.; Calegari, F.; Cireasa, R. XUV induced hydrogen migration in 5-halouracil. J. Phys. Conf. Ser., 2015, 635, 112131.

${ }^{27}$ Çarçabal, P.; Descamps, D.; Petit, S.; Mairesse, Y.; Blanchet, V.; Cireasa, R.; Using high harmonic radiation to reveal the ultrafast dynamics of radiosensitiser molecules, Faraday Discuss., 2016, 194, 407425.

${ }^{28}$ Månsson, E. P.; De Camillis, S.; Castrovilli, M. C.; Galli, M.; Nisoli, M.; Calegari, F.; Greenwood, J. B.; Ultrafast dynamics in the DNA building blocks thymidine and thymine initiated by ionizing radiation. Phys. Chem. Chem. Phys., 2017, 19, 19815-19821.

${ }^{29}$ Micciarelli, M.; Curchod, B. F. E.; Bonella, S.; Altucci, C.;Valadan, M.; Rothlisberger, U.; Tavernelli, I.; Characterization of the Photochemical Properties of 5-Benzyluracil via Time-Dependent Density Functional Theory, J. Phys. Chem. A, 2017, 121, 3909-3917

${ }^{30}$ Micciarelli, M.; Valadan, M.; Della Ventura, B.; Di Fabio, G.; De Napoli, L.; Bonella, S.; Röthlisberger, U.; Tavernelli, I.; Altucci, C.; Velotta, R.; Photophysics and Photochemistry of a DNA-Protein CrossLinking Model: A Synergistic Approach Combining Experiments and Theory J. Phys. Chem. B, 2014, 118, 4983-4992;

${ }^{31}$ Micciarelli, M.; Altucci, C.; Della Ventura, B.; Velotta, R.; Tosa, V.; Pérez, A.B.G.; Rodriguez,M.P.; de Lerac, A.R.; Bende, A.; Low-lying excited-states of 5-benzyluracil, Phys. Chem. Chem. Phys., 2013,15, 7161-7173

${ }^{32}$ Chiarinelli, J. et al. Insights in the fragmentation of glycine by PEPICO experiments. Phys.Chem.Chem.Phys (2018), DOI: 10.1039/C8CP03473G.

${ }^{33}$ Falzon, C. T.; Wang, F.; Understanding glycine conformation through molecular orbitals. J. Chem. Phys., 2005, 123, 214307-214319.

${ }^{34}$ Kuleff, A. I.; Cederbaum, L.S. Charge migration in different conformers of glycine: The role of nuclear geometry. J. Chem. Phys. 2007, 338, 320-328

${ }^{35}$ Jiang,Y.H.; Rudenko, A.; Herrwerth, O.; Foucar, L.; Kurka, M.; Kühnel, K. U.; Lezius, M.; Kling, M.F.; van Tilborg, J.; Belkacem, A.; et al. Ultrafst Extreme Ultraviolet Induced Isomerization of Acetylene Cations. Phys. Rev. Lett. 2010, 105, 263002.

${ }^{36}$ Nisoli, M.; De Silvestri, S.; Svelto, O.; Szipocs, R.; Ferencz, K.; Spielmann, C.; Sartania, S.; Krausz, F. Compression of high-energy laser pulses below 5 fs. Opt. Lett. 1997, 22,522-524.

${ }^{37}$ Belshaw, L.; Calegari, F.; Duffy, M. J.; Trabattoni, A.; Poletto, L.; Nisoli, M.; Greenwood, J. B. Observation of Ultrafast Charge Migration in an Amino Acid. J.Phys.Chem.Lett. 2012, 3, 3751-3754. 